\title{
Religious Group Identification and Inter-Religious Relations: A Study Among Turkish-Dutch Muslims
}

\author{
Maykel Verkuyten \\ Utrecht University
}

Following social identity theory, this research examines the relationship between group identification and intergroup relations by focusing on religion. Religious as well as Dutch national group identification was examined among Turkish-Dutch Muslims. Identification was studied in relation to general affective ratings of multiple religious groups (Muslims, Christians, Hindustanis, Jews and non-believers) and the endorsement of Islamic group rights. The results show that Muslim identification was more like a nominal (high or 'total' identification) than a continuous variable, and that many participants showed low identification with the national group. The affective ratings of religious out-groups were quite negative, particularly of the Jews and non-believers. Muslim identification was positively and strongly related to feelings toward the religious in-group and to the endorsement of Islamic group rights. National identification was positively related to feelings toward the religious out-groups, but only for 'total' Muslim identifiers, supporting the mutual intergroup differentiation model. The findings are discussed in relation to social psychological thinking about group identification and the importance of religion for intergroup relations.

KEYWORDS minority groups, national identity, religious group relations, religious identification

A Central assumption of social identity theory (SIT; Tajfel \& Turner, 1986) is that a positive social identity is typically based on favorable intergroup comparisons. Brown (2000) argues that a plausible inference to draw from this assumption is that identification with a group is positively related to the tendency to favor that group over other groups. People with high and low psychological commitment to their group (high and low identifiers) can be expected to differ in their reactions and evaluations.
There is considerable empirical evidence that in an intergroup situation those with high ingroup identification are more likely to show a variety of group level responses relative to those

\footnotetext{
$\overline{\text { Author's note }}$

Address correspondence to Maykel

Verkuyten, Faculty of Social Sciences,

Utrecht University, Heidelberglaan 2, 3584

CS Utrecht, The Netherlands

[email: M.Verkuyten@fss.uu.nl]
} 
shown by low identifiers (see Ellemers, Spears, \& Doosje, 1999).

However, not all studies support the link between in-group identification and in-group favoritism and the assumption of this link has also been criticized theoretically (e.g. Turner, 1999). A positive correlation between individual differences in group identification and individual differences in the degree to which the in-group is favoured over an out-group is not always found and can be quite weak (see Hinkle \& Brown, 1990; Mullen, Brown, \& Smith, 1992). In addition, Turner (1999; see also McGarty, 2001; Turner \& Reynolds, 2001) has criticized the idea of a simple positive correlation between identification and in-group favouritism because SIT argues that in-group favouritism is a function of, for example, status positions and beliefs about the nature of the groups and the intergroup context. Furthermore, group identification is a multifaceted construct that can be examined in various ways (see Ashmore, Deaux, \& McLaughlin-Volpe, 2004), and there is also the possibility of dual or hybrid identities (Verkuyten, 2005). Turner (1999, p. 22) further argues that it is important to focus on identities that "correspond to the subjective division of the social world by the subjects in relation to the intergroup attitudes obtained'. The identities should have real meaning and the evaluative dimensions used for assessing intergroup relations should be relevant in relation to various out-groups. Most social psychological studies have examined identification processes among student groups and the in-group favouritism found is typically due to a more positive evaluation of the in-group compared to a less positive or neutral evaluation of an out-group. Few studies have focused on real-world situations where group identification can be very strong and clear negative out-group reactions and evaluations may exist.

The present study focuses on religious and Dutch national group identification among Turkish-Dutch Muslims. Identification is studied in relation to general affective ratings of multiple religious out-groups and the endorsement of Islamic group rights. I examined, first, the nature of Muslim and Dutch group identification and their interrelationship. Second, the focus was on the associations of these group identifications with feelings toward Muslims, Hindustanis, Christians, Jews, and non-believers. Third, both group identifications were examined in relation to the endorsement of Islamic group rights in the Netherlands. With this study, I hope to make a contribution to a further understanding of the important processes of group identification. In particular, I will examine the assumed continuous nature of group identification and will discuss the role of dual identification. In addition, although religion is an important dimension for defining a positive social identity in comparison to dissenters and non-believers, social psychology has not paid much attention to religious identity (but see Argyle \& Beit-Hallahmi, 1975; Batson \& Burris, 1994; Blaine \& Crocker, 1995). Religion unifies the community of believers around a consensus of values and truths, and in doing so makes meaningful in-group and out-group distinctions which contribute to social divisions and current conflicts in many parts of the world.

\section{Religious identification}

There is a great deal of variation and inconsistency in the way that group identification is conceptualized and measured (see Ashmore et al, 2004; Cameron, 2004; Jackson \& Smith, 1999). For example, a distinction among various dimensions or elements of identification is made, such as evaluation, importance and attachment. Group identification is further interpreted in terms of situational sensitive self-categorizations, but also in terms of more stable differences in the degree to which psychologically central and valued group memberships have developed. The former interpretation focuses on the changing ways that people define themselves and the extent to which they feel attached to a specific group in a specific context (e.g. Ellemers et al., 1999). The latter one argues that some people, for whatever reason, are more inclined than others to see themselves as a group member and to value their group membership (e.g. Phinney, 1992).

In both interpretations, group identification can be considered as an individual difference variable which affects various group level 
responses. Group identification, for example, is an important factor affecting a person's readiness to use a social category for self-description, and people who feel highly committed to their group are inclined to act in terms of their group membership. Group identification implies that collective beliefs and values that characterize the in-group become normative and part of the psychological self. People start to think, feel and act in terms of the way that the in-group is understood. These group understandings can be relatively stable or enduring reflecting, for example, cultural features, but they are also responsive to social events and current threats (Tajfel \& Turner, 1986).

Triandis (1992) points out that in some collectivist cultures one either is or is not a member of the in-group. In these cultures, group identification is not so much a matter of degree and one cannot be more or less identified with a group: group identification is more of a nominal rather than a continuous variable. The orientation and commitment to the in-group is normative and total, rather than optional and differing in strength. Religious group identification can be similar. Religion is often of profound importance to people's lives and religious groups are among the more salient buttresses of identity. The lives of observant believers are organized around their religious beliefs, values and practices. These ideas and values involve religious truth-claims and absolute moral principles that define what it means to be a believer of a particular religion and that lead to dogmatic thinking (Altemeyer, 2002). Islam is a religion that presents guidelines, referred to in the Quran (1:6) as the 'straight way', for living in accordance with the will of Allah. These fundamental principles are known as the Five Pillars of Islam. The first pillar is the Shahada or declaration of faith and has a central place in the lives of Muslims. ${ }^{1}$ A person becomes a Muslim with the declaration of the Shahada in front of two witnesses, and one either is a Muslim who is committed to Islam or one is not.

Research has shown that for Muslims living in Western Europe, religion has great importance in the way they live their lives. In a nation-wide study in Great Britain, Modood et al. (1997) found that $74 \%$ of Muslim participants indicated that their religion was 'very important' in living their lives and 21\% said 'fairly important'. Furthermore, around $80 \%$ indicated that they visited a mosque once a week or more. In comparison, the highest percentage for 'very important' for the Hindu, Sikh, Catholic and Church of England participants was $46 \%$ for the Sikhs.

Among a representative sample from the city of Rotterdam, Phalet and Güngör (2004) found that Islam was considered 'very meaningful and important' in one's life by $87 \%$ of the Turkish and $96 \%$ of the Moroccan population. These percentages were similar for younger (18-30 years of age) and older participants ( $>30$ years). In addition, around two-thirds of the Turks and Moroccans had a very strong Muslim identity. For the great majority of Muslims, Muslim identity was a given and not being a Muslim was not a real option. The same has been found in surveys in Brussels, Belgium (Phalet, 2004), and in other European countries (Haddad \& Smith, 2001; Vertovec \& Rogers, 1999).

The data for the Rotterdam study were collected in 1999 but it is highly unlikely that these percentages have dropped. In the Netherlands a policy of multiculturalism was adopted in the 1980s in response to the increased influx of 'foreigners'. The recognition that many 'guestworker' migrants would remain in the country led to a policy for 'integration with retention of the own identity' (Entzinger, 2003, p. 63). Dutch policies saw immigrants according to their group membership and not primarily as individuals. The 'pillarization' tradition of institutionalized pluralism provided a wide range of cultural opportunities and group rights, such as local voting rights for non-nationals and public funding of Islamic schools. However, much has changed since the 1980s (see Joppke, 2004). The previous 'ethnic minorities policy' has gradually been replaced by a policy of civic integration (Entzinger, 2003) and in public debates multiculturalism has been described as a 'drama' and a 'failure', and assimilation has been proposed as the only viable option (e.g. Schnabel, 2000). In the last five years in the Netherlands, Islam has increasingly become 
the 'negative other'. In the Dutch media, Islam has become symbolic for problems related to ethnic minorities and immigration (see Ter Wal, 2004) and some politicians have defined Islam as a backward religion and Muslims as a 'fifth column', and have argued that 'a cold war against Islam is unavoidable' (see Verkuyten \& Zaremba, 2005).

As a result, the current public discussion strongly focuses on the need to compel Islamic groups to assimilate because they are a threat to Dutch values and identity. Thus, the emphasis on Islamic groups has become more prominent but it is not new. In the Netherlands, these groups are at the bottom of the ethnic hierarchy and they have been the prototypes or paradigmatic examples of minority groups for quite some time (Hagendoorn, 1995). Hence, Islamic groups clearly face high levels of threat to the value of their religious identity and the public condemnation of Islam and the plea for assimilation can lead to strong in-group identification among these groups (Verkuyten \& Zaremba, 2005). Thus, it was expected that Muslim identity would be very important for most Turkish-Dutch participants, making Islamic group identification more like a nominal rather than a continuous variable.

\section{Dutch identification}

In acculturation research, Berry's (1984) twodimensional model has become one of the most used frameworks. The model has been supported empirically in various studies (e.g. Ryder, Alden, \& Paulhus, 2000; Ward \& Rana-Deuba, 1999) and proposes a combination of culture maintenance and mainstream contacts, resulting in four different acculturation positions: assimilation, separation, integration and marginalization. By analogy with the two-dimensional model of acculturation, ethnic identification and identification as a member of the new society can be thought of as two dimensions that vary independently. Hutnik (1991) developed such a model, independently of Berry's work.

Traditionally, identification with one's own ethnic group was considered to be inversely related to identification with other groups, in particular the majority group. Research presented participants with a forced-choice test to measure ethnic identification, such as in studies using black and white dolls or questions such as 'do you feel Dutch or Turkish'. As a result, identification was studied as an either/or phenomenon and the possibility of a hyphenated or dual identity was disregarded. The result was, for example, the assumption that the more strongly people identified with their own minority group, the more they would distance themselves from others.

However, in a situation where people are free to describe themselves, they do not always use this dichotomous scheme of group identification (e.g. Hutnik, 1991; Sanchez \& Fernandez, 1993). Findings from cross-cultural studies suggest that group identification is not necessarily a singular given but may be constituted of hyphenated identities that indicate varying degrees of identification with both the ethnic minority group and the majority group simultaneously. For example, for many Turks living in the Netherlands it is often not a question of being Turkish or Dutch but a question of the extent to which they feel Turkish as well as the degree to which they feel Dutch (Verkuyten, 2005). They can consider themselves members of their ethnic in-group but also as having to relate to, if not quite be members of, the majority group.

These identities do not have to contradict each other or get in each other's way because they are of different kinds: they are differently defined or situated on different levels of abstraction. One can be a member of an ethnic group as well as a superordinate national category. There is little problem as long as these identities are not defined on the same level of abstraction and in contrasting or competing terms. Depending on the situation the one or the other is relevant and becomes salient.

However, different identities do sometimes get in each other's way. For Polish Tatars, for example, being simultaneously a Tatar, a Muslim and a Pole is central to their self-understanding (see Cieslik \& Verkuyten, 2006). Islam as practiced by the Polish Tatars is the main characteristic distinguishing them from the Catholic Poles. The Tatars perceive themselves as real Muslims 
even though theirs has developed as a specialized local variant of Islam. Furthermore, the social and cultural aspects of their religious life are central for maintaining Tatar ethnic solidarity. In contrast, Catholicism is strongly connected with the idea of the Polish nation and a central aspect of 'being Polish' (Warminska, 1997). Polish national identity is largely based on being Catholic and includes negative stereotypes of other religions, particularly Islam. Hence, the Tatars' claim to Polishness can be problematic when their religious background is emphasized too much, making it difficult to find the right balance between being Polish and Muslim at the same time.

In the Netherlands, being simultaneously a Muslim and a Dutch national is often not easy. In public debate the secular nature and Christian heritage of Dutch society is increasingly emphasized. Among Turkish-Dutch people, a close association between Turkish and Muslim identification has been found $(r>.60)$, and several studies in the Netherlands have found that around a third of the participants of different ethnic minority and age groups indicate a dual or hyphenated identity (e.g. Turkish-Dutch), whereas about half of them identify only with their own group (e.g. only Turkish) and not with the Dutch (see Verkuyten, 2005). Thus, it was expected that two groups of participants could be distinguished: low and high Dutch identifiers.

\section{Multiple religious out-groups}

In general, there is a close relationship between religion and prejudice. The more religious an individual is, the more prejudiced he or she is likely to be (see Batson \& Burris, 1994; Scheepers, Gijsberts, \& Hello, 2002). Particularly, people whose religious beliefs provide clear-cut moral truths tend to be negative towards out-groups. Feelings towards out-groups are also related, however, to the intergroup situation (Tajfel \& Turner, 1986).

In the Netherlands, questions of religious and cultural differences and conflicts have become core issues in public and political debates. According to SIT, under identity threatening circumstances, people will try to maintain or restore a positive and distinct collective identity, for example by increased in-group favouritism. The public condemnation of Islam and the plea for assimilation implies that Islamic groups clearly face threats to the value of their religious identity. Other religious groups present a threat to the integrity of the Islamic in-group struggling to maintain a valuable and distinctive identity. To enhance the value and distinctiveness of their religious in-group, group members can derogate other religious groups (Rothgerber \& Worchel, 1997). Hence, we expected that the feelings towards religious out-groups would be rather negative.

However, there may also be differences in feelings towards various religious out-groups living in the Netherlands: e.g. Christians, Hindustanis, Jews and non-believers. Different out-groups can enjoy varying degrees of social acceptability. In relation to ethnicity, there is evidence for this in countries such as Canada, the United States, the former Soviet Union and the Netherlands (for reviews see Hagendoorn,1995; Owen, Eiser, \& McFaul, 1981), and among ethnic majority and minority group members (Berry \& Kalin, 1979; Verkuyten, Hagendoorn, \& Masson, 1996).

There can be many reasons for the different evaluation of out-groups. For example, research has shown (see Hagendoorn, 1995; Verkuyten et al., 1996) that cultural differences, negative stereotypes and the degree to which out-groups are perceived as threatening the status and interests of the in-group play a role. In addition, concerns about beliefs, values and norms that define the collective identity are important. Religious belief is not about personal preferences or social conventions, but about convictions. It is concerned with moral good and divine truth that is difficult to reconcile with moral and epistemic diversity. The observant believer believes that he or she is right and will find it difficult to have positive feelings towards nonbelievers that implicitly challenge his or her life. Atheism cannot do without believers, and vice versa. In the Rotterdam study, around $45 \%$ of the Islamic participants indicated that they had 'completely no sympathy' for non-believers (Phalet \& Güngör, 2004). Hence, we expected 
that the feelings towards non-believers would be more negative than those towards Christians and Hindustanis. People of the latter two groups do at least consider religion important and Christianity has, of course, many similarities with Islam.

In addition, we expected the feelings towards Jews to be quite negative. In many European countries, including the Netherlands, there is a growing concern about increased antiSemitism, which certainly is not only limited to Islamic groups but which has also been manifest in, for example, mosques across Europe and among Muslim youth (Antisemitism Research, 2002). One source for this antisemitism is the conflict between Palestinians and Israelis, and between observant Muslims and observant Jews in particular. The concern about antiJewish tendencies among Muslims is further illustrated by the many books and websites that find it necessary to argue that Islam actually denounces antisemitism.

The affective ratings towards the various religious out-groups living in the Netherlands were expected to be related to Muslim and Dutch national identification. Participants with a very strong Muslim identification were expected to be more negative than participants with a less strong Muslim identification. In addition, higher Dutch identification was expected to be associated with less negative religious outgroup feelings. The reason for this expectation is that a common national identity implies that religious group distinctions can be subsumed into a superordinate category. This shared category can reduce negative feelings because the religious out-group members become fellow national in-group members (Gaertner, Dovidio, Anastasio, Bachman, \& Rust, 1993; Gaertner, Mann, Murrell, \& Dovidio, 1989). Hornsey and Hogg (2000) have shown that such a reduction is particularly likely when the superordinate (national) category membership is combined with a strong (religious) subgroup identity (see also Hewtsone \& Brown, 1986). Such a combination helps to reduce threats to a valued identity that may result from assimilation to the national category. This means that for strong Islamic group identifiers in particular, higher Dutch identification can be expected to be associated with less negative religious out-group feelings. Hence, an interaction effect between Dutch and Islamic group identification was expected.

\section{Islamic group rights}

Berry and Kalin (1995) argued that groups are more in favour of cultural diversity and group rights when they see advantages for themselves. Several theories have emphasized the role of group interests in the dynamics of intergroup relations (e.g. Blumer, 1958; Bobo, 1999; Tajfel \& Turner, 1986). For religious minority groups, minority rights offer the possibility of maintaining and expressing their own distinctive religious identity, and obtaining more equal social status in society. Hence, we can expect that the participants will support Islamic group rights. In addition, the more strongly Muslims identify with their religious in-group, the more likely they are to consider it important to express and preserve their own religion and to participate as religious group members in social and political life. In contrast, from the perspective of common group identity (Gaertner et al., 1993), it can be expected that Dutch identification will be negatively related to the attitude towards Islamic group rights. This is particularly likely in the context of a very strong Muslim identity that minimizes feelings of identity threat (Hornsey \& Hogg, 2000).

\section{Method}

\section{Participants}

A questionnaire was used and in total there were 217 Turkish-Dutch participants. On an open-ended question, 206 of these participants described themselves as Muslim (Sunni), and these participants have been included in the analyses. Of these participants $68.8 \%$ were males and $31.2 \%$ females. The participants were between 16 and 62 years of age and their mean age was $30.18(S D=10.63)$. The participants were recruited in the Utrecht region and were asked to participate in research on contemporary social issues. In the introduction it was explained that the study was on people's opinions about 
the 'Netherlands and Dutch society' and that we wanted to know what people thought about the societal situation in the country. The study was presented as focusing on opinions of people in general, but the participants were recruited by a Turkish-Dutch assistant. The participants received $€ 5$ for their cooperation.

\section{Measures}

Muslim group identification was assessed by six items using 7-point scales (with 1 as 'disagree strongly', 4 as 'neutral', and 7 as 'agree strongly'). The items are similar to questions used in various social psychological studies and in Dutch studies on ethnic identification (see Verkuyten, 2005). The items were: 'My Muslim identity is an important part of my self'; 'I identify strongly with Muslims'; 'I feel a strong attachment to Muslims'; 'Being a Muslim is a very important part of how I see myself'; 'I am proud of my Islamic background'; and 'I feel a strong sense of belonging to Islam'. Cronbach's alpha was .94.

Dutch identification was assessed by four items using the same 7-point scale. The items were: 'I identify with Dutch people'; 'I feel that I am Dutch'; 'I feel connected to the Netherlands'; and 'Being Dutch is an important part of how I see myself'. Cronbach's alpha was .85.

In order to measure religious group feelings, the participants were given the well-known 'feeling thermometer'. This thermometer has been successfully used in different studies of both ethnic majority and ethnic minority group participants, including in the Netherlands (e.g. Dijker, 1987; Verkuyten \& De Wolf, 2002). It is intended as a global measure of in-group and out-group feelings. The exact wording of the instructions was:

Use the 'feeling thermometer' to indicate whether you have positive or negative feelings about different religious groups living in the Netherlands. You may use any degree between 0 and 100 , but you have to choose one. 100 degrees indicates very positive or warm feelings and zero degrees indicates very cold or negative feelings.

Following the instruction, five religious groups were listed in the following order: Hindustanis, Christians, Muslims, Jews and non-believers.
Under each target group a scale was presented running from 0 to 100 .

For assessing the attitude towards Islamic group rights in the Netherlands, eight items that are relevant in the Dutch context were used. These items were partly taken from Verkuyten and Yildiz (2006) and focus on public rights. The items were: 'The right to establish own Islamic schools should always exist in the Netherlands'; 'some Islamic holy days should become official Dutch holidays'; 'Dutch TV should broadcast more programes by and for Muslims'; 'in the Netherlands the wearing of a headscarf should not be forbidden'; ' Muslims should establish an Islamic political party'; 'The Dutch government does not really listen to what Muslims want'; and 'in the Netherlands, more measures against discrimination of Muslims are needed'. Items were measured on scales ranging from 1 (disagree strongly) to 7 (agree strongly), and the eight-item scale was internally consistent with Cronbach's alpha which was .88. A higher score indicated a stronger endorsement of Islamic group rights.

\section{Results $^{2}$}

\section{Group identifications}

On the basis of a 7-point scale, the mean score indicated strong Muslim group identification $(M=5.81, S D=1.79)$. The distribution was negatively skewed (-1.45) and the mode was 7.0. In total, $50.5 \%$ of the participants had a score of 7 indicating that for half of the sample their Muslim identity was an integral or inextricable part of how they saw themselves. Because of the skewness of the distribution, a median split was used for making a distinction between high $(M=4.59, S D=1.88)$ and 'total' $(M=7.0)$ Muslim group identification.

The mean score for Dutch identification was $3.80(S D=1.68$, median 4.0), which is around the neutral midpoint of the scale. Of the participants, $46.6 \%$ had a score below the midpoint indicating low identification with the Dutch, and $45.7 \%$ had a score above the midpoint indicating high Dutch identification $(7.7 \%$ at the midpoint). The high and total Muslim identifiers differed significantly for Dutch 
identification, $t(206)=4.73, p<.001$. Dutch identification was stronger in the former group compared to the latter $(M=4.33, S D=1.53$, and $M=3.28, S D=1.68$, respectively).

Classification of the participants in four identity positions can be achieved by using the bipartite split of the two identification scales. For Dutch identification, the scores at the neutral midpoint of the scale were disregarded. The results are shown in Table 1. All four combinations of group identification are evident, but two combinations were predominant: (1) total Muslim identification and low Dutch identification; and (2) high Muslim identification and high Dutch identification. Both measures were significantly and negatively related but not strongly $(\mathrm{Phi}=-.24, p<.01)$.

\section{Thermometer ratings}

For the thermometer questions the focus was on the affective ratings of Muslims, Hindustanis, Christians, Jews and non-believers. The rating of the Muslims was negatively related to the

Table 1. Participant Identification (\%) with the Muslim group (high versus total) and with the Dutch (de-identification versus identification)

\begin{tabular}{lcc}
\hline & \multicolumn{2}{c}{ Muslim identification } \\
\cline { 2 - 3 } & High & Total \\
\hline Dutch identification & & \\
Low & $19.3 \%$ & $31.3 \%$ \\
& $(N=37)$ & $(N=60)$ \\
High & $30.7 \%$ & $18.8 \%$ \\
& $(N=59)$ & $(N=36)$ \\
\hline
\end{tabular}

$\chi^{2}(1,192)=11.02, p<.001$. feelings towards non-believers $(-.41, p<.001)$, but not significantly towards the other religious out-groups. The affective ratings of the four outgroups were significantly and positively related $\left(p_{\mathrm{s}}<.001\right.$; range between .37 and .58$)$.

A repeated measures multivariate analysis of variance was conducted with the five religious groups' ratings as a repeated measures factor. Muslim identification (high versus total) and Dutch identification (low versus high) were the independent factors. The analysis yielded a significant main effect for group ratings, $F(4,206)=139.28, p<.001$. As shown in Table 2 , participants clearly had the most positive feelings towards Muslims. For the religious outgroups, the mean score for the Christians was around the neutral midpoint (50) of the scale, followed by the Hindustanis, the non-believers and then the Jews. The feelings towards the latter two groups were quite negative. Around a third of the participants indicated extremely negative feelings (score zero) towards these two groups, and more than half scored below the neutral midpoint of the scale. In contrast, more than half of the participants indicated extremely positive feelings (score 100) towards Muslims. Except for the difference in feelings towards Jews and non-believers, all pair-wise comparisons between the five groups were significant $\left(p_{\mathrm{s}}<.01\right)$. In addition, the scores for the Muslims and Christians were significantly above the neutral midpoint of the scale $(t=20.66, p<$ .001 , and $t=2.21, p<.05$, respectively), whereas the scores for the Hindustanis, Jews and nonbelievers were below the midpoint $(t=1.76$, $p=.08, t=6.38, p<.001$ and $t=5.49, p<.001$, respectively).

Table 2. Percentages, mean scores, and standard deviations for the thermometer ratings of the five religious groups

\begin{tabular}{lrrrrrrr}
\hline & \multicolumn{7}{c}{ Thermometer ratings } \\
\cline { 2 - 8 } & \multicolumn{1}{c}{0} & $10-40$ & 50 & $60-90$ & 100 & Mean & SD \\
\hline Muslims & 2.4 & 3.9 & 6.7 & 33.3 & 51.7 & 83.8 & 23.7 \\
Christians & 9.1 & 13.8 & 30.6 & 41.2 & 5.3 & 53.9 & 25.7 \\
Hindustanis & 12.4 & 23.0 & 31.1 & 28.7 & 4.8 & 46.7 & 27.1 \\
Non-believers & 31.4 & 19.5 & 18.7 & 23.7 & 6.7 & 37.3 & 33.3 \\
Jews & 33.5 & 21.9 & 18.2 & 20.7 & 5.7 & 35.3 & 33.4 \\
\hline
\end{tabular}


The analysis showed a significant interaction effect between group ratings and Muslim identification, $F(4,206)=27.67, p<.001$. Simple main effect analyses indicated an effect for identification on the feelings towards Muslims and towards non-believers. As shown in Table 3, compared to high identifiers the participants with total Muslim identification indicated more positive feelings towards Muslims (explaining $28 \%$ of the variance), and more negative feelings towards non-believers. Muslim identification was not related to the feelings towards Christians, Hindustanis and Jews.

There was also a significant interaction effect between group ratings and Dutch identification $(F(4,206)=3.30, p<.01)$. Simple main effects analyses showed significant effects $\left(p_{\mathrm{s}}<.05\right)$ for the four religious out-groups, but not for the Muslim in-group (see Table 3). Compared to low identifiers, Dutch identifiers reported less negative feelings towards all four out-groups.

As expected, these effects for out-group feelings were qualified by a three-way interaction effect between group ratings, Muslim identification and Dutch identification, $F(4,206)=2.97, p<.05$. Further analyses indicated significant effects for the four religious out-groups $\left(p_{\mathrm{s}}<.05\right.$, for the Jews, $p=.054)$. As shown in Figure 1, Dutch identification turned out to be related to the out-group ratings for the participants with total Muslim identification only. For these participants, Dutch high identifiers had less negative feelings towards religious out-groups than Dutch low identifiers. The participants with total Muslim identification who also had low identification with the Dutch had the most negative or cold feelings towards the religious out-groups.

\section{Islamic group rights}

The mean score for Islamic group rights indicated that the participants were in favour of special rights for Muslims $(M=5.52, S D=1.34$, median $=5.87)$. Regression analysis was used to predict the endorsement of Islamic group rights. Muslim identification and Dutch identification as well as their interaction were used as predictors. In the regression equation, the high Muslim identifiers were compared with the total identifiers using contrast coding (Aiken \& West, 1991). In this procedure the criterion measure is regressed on the predictors and their interactions with the contrast between the two groups. The contrast is coded -1 and +1 respectively for the high and total Muslim identifiers.

The regression model explains no less than $48 \%$ of the variance in the endorsement of Islamic group rights, $F(3,189)=57.25, p<.001$. Muslim identification was a significant and strong positive predictor $(\beta=.73, t=9.51$, $p<.001)$. The total Muslim identifiers were more in favour of Islamic group rights than high Muslim

Table 3. Mean thermometer ratings (and standard deviations) for participants with high and total Muslim identification, and for participants with low and high Dutch identification

\begin{tabular}{|c|c|c|c|c|c|c|}
\hline & \multicolumn{3}{|c|}{ Muslim identification } & \multicolumn{3}{|c|}{ Dutch identification } \\
\hline & High & Total & $F$-value & Low & High & $F$-value \\
\hline Muslims & $\begin{array}{c}71.3 \\
(27.1)\end{array}$ & $\begin{array}{l}96.0 \\
(9.4)\end{array}$ & $74.34 * * *$ & $\begin{array}{c}86.6 \\
(24.1)\end{array}$ & $\begin{array}{c}82.4 \\
(23.2)\end{array}$ & 0.36 \\
\hline Christians & $\begin{array}{c}56.2 \\
(21.9)\end{array}$ & $\begin{array}{c}51.7 \\
(18.9)\end{array}$ & 0.16 & $\begin{array}{c}46.6 \\
(26.9)\end{array}$ & $\begin{array}{c}61.6 \\
(23.2)\end{array}$ & $16.17 * * *$ \\
\hline Hindustanis & $\begin{array}{c}49.8 \\
(24.8)\end{array}$ & $\begin{array}{c}43.7 \\
(29.0)\end{array}$ & 1.31 & $\begin{array}{c}41.5 \\
(28.0)\end{array}$ & $\begin{array}{c}51.1 \\
(25.8)\end{array}$ & $4.88^{*}$ \\
\hline Non-believers & $\begin{array}{c}49.2 \\
(31.7)\end{array}$ & $\begin{array}{c}25.8 \\
(30.8)\end{array}$ & $23.53 * * *$ & $\begin{array}{c}29.1 \\
(32.3)\end{array}$ & $\begin{array}{c}44.3 \\
(33.0)\end{array}$ & $4.95^{*}$ \\
\hline Jews & $\begin{array}{c}38.2 \\
(32.0)\end{array}$ & $\begin{array}{c}32.5 \\
(34.6)\end{array}$ & 0.15 & $\begin{array}{c}26.3 \\
(30.3)\end{array}$ & $\begin{array}{c}43.2 \\
(34.1)\end{array}$ & $15.31^{* * * *}$ \\
\hline
\end{tabular}

$* p<.05 ; * * * p<.001$. 


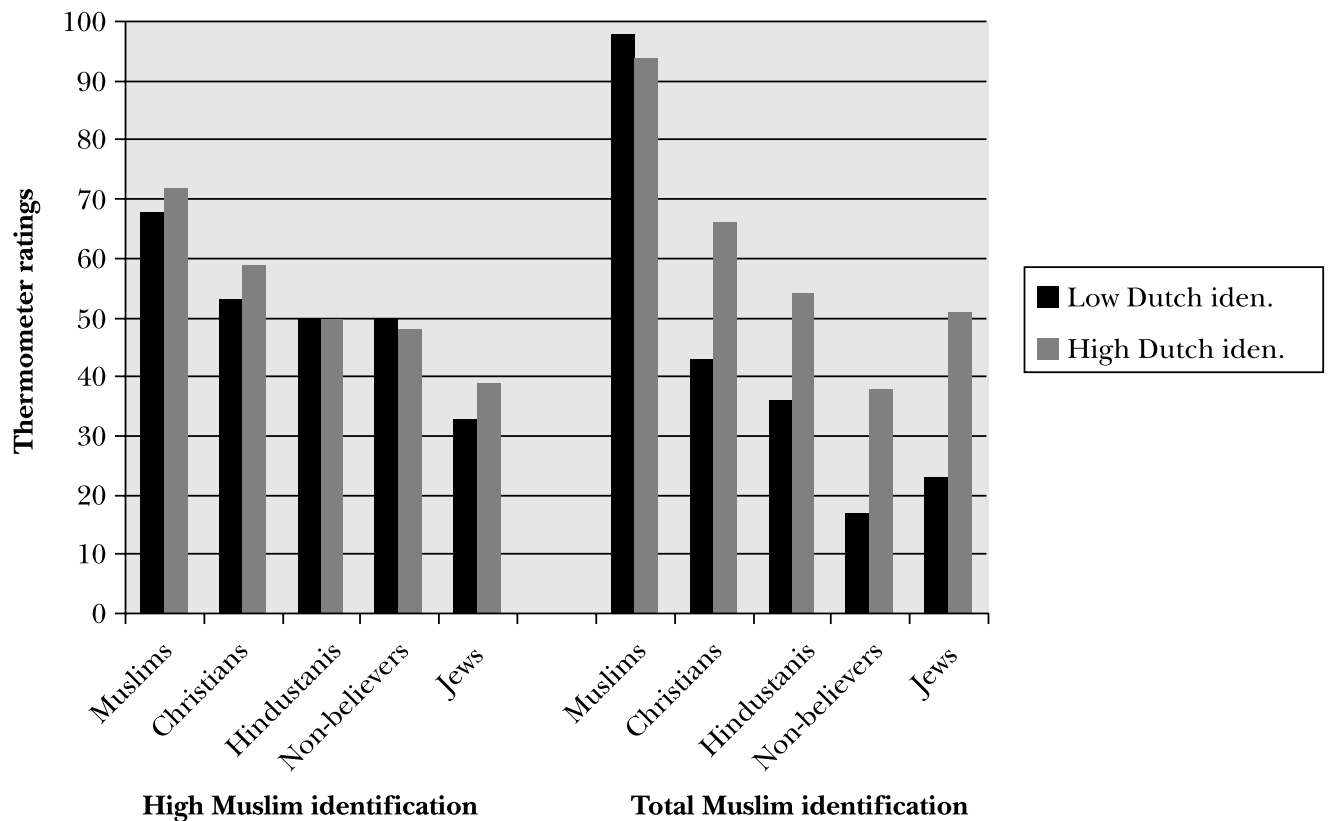

Figure 1. Mean thermometer ratings by Muslim and Dutch identification

identifiers $(M=6.46, S D=0.61$, and $M=4.56$, $S D=1.19$, respectively). Dutch identification did not make a significant contribution to the prediction of the endorsement of Islamic group rights. The interaction between Muslim and Dutch identification was also not significant, but had a marginal effect $(\beta=-.21, t=1.62$, $p=.098)$.

In an additional regression analysis, the continuous centered score of Dutch identification was used as a predictor (Aiken \& West, 1991). In this analysis, the interaction effect between Muslim identification and Dutch identification was significant $(\beta=-.27, t=2.07, p<.05)$. Separate regression analyses for high Muslim identifiers and for total Muslim identifiers showed that Dutch identification was not significantly associated with Islamic group rights for the former group $(\beta=.12, t=1.17, p>.10)$. For the latter group this association was negative $(\beta=-.22, t=2.32, p<.05)$. Thus, Dutch identification was related to lesser endorsement of Islamic group rights for participants with total Muslim identification, whereas for the high Muslim identifiers, Dutch identification was not related to Islamic group rights.

\section{Discussion}

Identification establishes a psychological link between the individual and the group. As soon as people identify with their group, that group becomes the basis for thinking, feeling and acting. Hence, for social psychologists working within the tradition of social identity theory, essential questions are, 'how do people identify with a group, and precisely what are the consequences of such identification' (Hogg \& Abrams, 1988, p. 2, their italics). Group identification is conceptualized in various ways (e.g. Ashmore et al., 2004; Cameron, 2004; Jackson \& Smith, 1999), and social psychological studies have examined various groups and different intergroup situations. However, few studies (e.g. Argyle \& Beit-Hallahmi, 1975; Batson \& Burris, 1994; Blaine \& Crocker, 1995) have focused on religious identification and feelings towards multiple religious out-groups, and few studies 
have examined dual or hyphenated identities and the attitude towards religious group rights. This is unfortunate because religious distinctions are among the most important and most problematic ones in many present-day societies and religion is an important dimension for defining a positive identity.

This study focused on religious and Dutch national identification among Islamic (Sunni) Turkish-Dutch participants. The results show that for most participants, Muslim identity is very important. No less than half of the participants had the highest possible score on the six-item Muslim identification measure indicating 'total' group identification. Hence, for many participants, Muslim identity does not seem to be optional or a matter of strength of identification. Other Dutch studies among Muslims have found similar results (e.g. Phalet \& Güngör, 2004). This total Muslim identification is probably related to global and national developments. For example, the increased global tensions and divergences between the Western and Islamic world may also force Turkish-Dutch Muslims to a position of having to defend and stress their religion. In addition, in the Netherlands, the public condemnation of Islam and the plea for assimilation has increased the salience and importance of Muslim identity (Verkuyten \& Zaremba, 2005). Islamic immigrant groups face high levels of threat to the value of their religious identity which can lead to increased in-group identification among these groups.

However, the total religious identification found is probably also related to the nature of monotheistic religions in general, and Islam in particular. Very strong Muslim identification among West European immigrants was also found in the 1990s when the intergroup tensions were much less strong (e.g. Modood et al., 1997). In addition, being a Muslim seems to imply a normative group commitment that is related to Islamic religion. For many Muslims, the declaration of faith symbolizes one's belief and commitment to Islam: one either is a believer or one is not. Religion is about convictions and divine truths, and for most observant believers, the core of their religious identity is non-negotiable, making the idea of religious changes or adaptations an oxymoron.

The results further indicate the importance of examining dual or hyphenated identities. In social psychology, there is increasing interest in the fact that most individuals are simultaneously members of multiple social groups. There is, for example, research on the effects of cross-categorization on in-group bias (e.g. Crisp, Hewstone, \& Rubin, 2001; Deschamps, 1977, and on social identity complexity (e.g. Brewer \& Pierce, 2005; Roccas \& Brewer, 2002). However, for studying dual and hyphenated identities the nature of the groups is also important. Language and culture, for example, differ from religion in that one can master more than one language and internalize more than one culture, whereas religious identity is exclusive (Zolberg \& Long, 1999). Cross-cutting memberships and dual identities are possible as among bilinguals and biculturals, but it is something else to be a 'Christian Muslim' or a 'Hindu Jew'.

This study examined religious and national identity. The results indicate that it is important to examine religious identification in relation to national group identification (see also Hutnik, 1991). In the Netherlands, it is often thought that Muslim identification implies low identification, or even de-identification, with the Dutch. Muslim identity is thought to be contradictory to Dutch national identification because of incompatible values, norms and beliefs. Our results showed a negative association between Muslim and Dutch identification, but they also indicated that a total Muslim identification does not necessarily imply low Dutch identification. Furthermore, around a third of the participants indicated high Muslim identification together with Dutch national identification. Hence, the finding that a large number of participants have a very strong Muslim identity does not imply that all of these immigrant people would not be interested in developing a sense of commitment to the nation.

The importance of examining dual identities is also evident from the results for the affective ratings of the various religious out-groups. Social identity theory is a theory about intergroup 
differentiation rather than out-group derogation, dislike and other forms of negative affect (Brown, 2000). The majority of social psychological studies focus on situations in which the in-group is evaluated a little more favourably than an outgroup. Few studies have examined situations in which there are clear negative feelings towards out-groups and in which these feelings differ for various out-groups (Brewer, 1999). The present results show that the affective ratings towards Christians, Hindustanis, Jews and nonbelievers were quite low, indicating neutral to negative or cold feelings. The mean scores for the Christians and Hindustanis as target groups were around the neutral midpoint of the scale, and the mean scores for Jews and non-believers were clearly negative, with around a third of the participants indicating the most negative score on the thermometer question (zero degrees). The results support the idea that religion can be an important dimension for making meaningful and strong in-group and out-group distinctions. Religion unifies a community of believers around a consensus of moral values and divine truths. The observant believer will feel that he or she is 'right' leading to dogmatic thinking (Altemeyer, 2002) and making it difficult to have positive feelings towards other religions, and to dissenters and non-believers in particular. The feelings towards non-believers were very negative. In addition, the affective rating towards the Islamic in-group was significantly and negatively related to the feelings towards non-believers only.

However, not only the nature of the group is important to understand out-group dislike and negative affect, but also the nature of the intergroup situation (Brewer, 1999; Tajfel \& Turner, 1986). The feelings towards Christians and Hindustanis were less negative than towards Jews. The negative feelings towards the latter group are most likely related to the growing anti-Jewish sentiments in present-day Islam, which is exacerbated by the Israeli-Palestinian conflict. In recent years, antisemitism has increased, particularly among Muslim populations around the world, including Western Europe (Antisemitism Research, 2002). Hence, the results indicate the importance of studying negative group relations in relation to different out-groups and in relation to political and ideological circumstances (Verkuyten \& Zaremba, 2005).

Dutch national identification was found to be positively associated with out-group feelings towards religious groups in the Netherlands. Compared to Dutch low identifiers, high national identifiers had a positive mean score towards Christians, a neutral score towards Hindustanis, and less negative scores towards Jews and nonbelievers. These results seem consistent with the common-group identity model for the reduction of in-group bias (Gaertner et al., 1989, 1993). A common national identity implies that religious group distinctions are subsumed into a superordinate category that can reduce negative feelings because the religious out-group members are fellow national in-group members. However, the results show a further significant interaction effect between Muslim and Dutch identification. The positive effects for Dutch national identification were only found for total Muslim identifiers. The most negative or cold feelings towards the religious out-groups were found among the total Muslim identifiers who identified to a low degree with the Dutch. In contrast, participants with total Muslim identification and high Dutch national identification had the most positive feelings (except towards the non-believers). Hence, a simultaneous awareness of both a common national identity and a strong emphasis on one's Muslim identity-dual identity-seems to be the best condition for relatively favourable feelings towards religious out-groups. This result is in agreement with Berry's (1984, 2005) acculturation model and with the mutual intergroup differentiation model (Hewstone \& Brown, 1986; Hornsey \& Hogg, 2000). The former model argues that the integration strategy results in the least intergroup conflict. The latter one argues that emphasizing a superordinate category is effective in promoting positive intergroup relations, provided that the integrity of the original subgroups is maintained. This latter model might be particularly adequate or relevant for minority groups that face high levels of identity threat and show strong group identification, such as Islamic minority groups in the western world. 
Muslim identification was also related to the affective rating of Muslims and the endorsement of Islamic minority group rights. Compared to high identifiers, total Muslim identifiers had more positive feelings towards Muslims and were more in favour of group rights. The differences were quite substantial because Muslim identification accounted for not less than $28 \%$ of the variance in the affect rating and for $48 \%$ of the variance in the endorsement of Islamic group rights. These results further show that the dichotomous distinction between high and total Muslim identification is an important one. Individuals who feel totally and normatively committed to their religious group did show very strong in-group favouritism and were also much more in favour of political demands for group rights. For the total Muslim identifiers, for example, the mean score for the endorsement of Islamic group rights was very high (6.46 on a 7-point scale).

The findings do not only have theoretical implications but they also raise practical issues. For one thing, there is the question of how group rights can be reconciled with the emphasis on individualism and meritocracy that is central in most western liberal states (Barry, 2001). Furthermore, an emphasis on groups and group rights can lead to reified group distinctions that endanger social unity and cohesion (Brewer, 1997). In addition, there is the question of how a very strong Muslim identity can go together with an accepting or tolerant attitude towards religious out-groups. The present results do not allow for much optimism but should not be taken to show that negative religious out-group feelings are intrinsic to Islam. Following social identity theory, it has been argued that group identification and intergroup relations should be examined in their wider social and political context. For example, the results also indicate that for total Muslim identifiers, Dutch national identification is related to more positive feelings towards religious out-groups and a less stronger endorsement of Islamic group rights. Hence, the meaning and implications of Muslim identification should be considered in relation to other group memberships and the intergroup situation.
This does not mean that the nature and content of the group identity is not important. Religious groups differ in terms of their identity defining beliefs, values and norms. Religion is about convictions and divine truths, and for most observant believers, the core of the religious identity is considered absolute and non-negotiable. But there are also differences between and within religious groups, such as between Hindustanis and Christians, and between Sunni and Shiite Muslims. These groups differ in various ways and the acceptance and tolerance of 'others' can be seen as more or less self-defining. Muslim identity and what represents the core of the religion is not a fixed given but is disputed and constructed in different ways and in the context of negotiating intergroup relations and organizing collective action (see Kahani-Hopkins \& Hopkins, 2002).

In evaluating the present results, some restrictions should be considered. For example, the study was correlational making it impossible to determine the causal direction of the effects. The arguments and analyses presented were based on social identity theory, but future research should examine the causal impact of religious identification. Furthermore, the order of the two group identification measures was not counterbalanced.

In addition, religious identification was measured with items that are commonly used in social psychological research (see Ashmore et al., 2004; Jackson \& Smith, 1999). However, the way that the items were phrased might have affected the results and a more 'extreme' phrasing could lead to a different distribution of scores. ${ }^{3}$ For example, instead of presenting participants with a statement like 'Being a Muslim is a very important part of how I see myself' one could phrase the statement as 'Being a Muslim is the only important part of how I see myself'. The latter statement is more concerned with the possible exclusionary nature of Muslim identification and therefore can shed additional light on the question of total religious identification. In addition, it seems important to examine in future studies different dimensions of religious identification, such as religious behaviors and practices (see Ashmore et al., 2004; Verkuyten, 2005). It is possible that 
for other dimensions, Muslim identification is more like a continuous variable. Furthermore, future studies could investigate religious identification among different Islamic groups, such as Alevite and Shiite, in different countries and among Islamic minority and majority groups, as well as among different religious groups.

An additional point in relation to group identification concerns the interpretation of the result for Dutch identification. This study used the standard social psychological practice of making a distinction between low and high identification. In doing so, participants scoring below the neutral midpoint of the scale ('disagree') were considered to indicate low Dutch identification. However, strongly disagreeing with an item such as 'I identify with Dutch people' could also indicate de-identification. Group identification can be resisted or rejected. Rather than low identification with one's group, someone may not want to belong to that group. He or she may want to keep a distance from the expectations and demands that follow from the group membership. Thus, de-identification rather than low identification can be the issue. Low identification with others or one's group does not seem the same as de-identification from others or one's group. As weak as it can be, in the former case there is a sense of belonging and commitment. In the second case, there is a rejection and distancing from the group and what it means and stands for. The consequences of both processes can be different, such as indifference towards the 'other' in the former case and an oppositional identity and counterculture in the latter (e.g. Ogbu, 1993). Hence, it seems important for social psychology to develop criteria and questions for making a distinction between low identification and de-identification, for example, by using self-categorization questions.

In conclusion, this study examined the relationship between group identification and intergroup relations by focusing on Muslim identity among Turkish-Dutch participants. Social psychology has not paid much attention to religious identity. This is unfortunate because religion is an important dimension for developing a positive social identity and religion is an important factor in social divisions and conflicts in many societies around the world. In addition, a study of religious identification can make a contribution to our thinking about the important processes of group identification. For example, such a study can question the standard practice of assuming that group identification is a continuous variable or a matter of degree. Furthermore, by also examining national group identification it was possible to focus on the role of dual identity. Future studies on both the origins and consequences of religious and dual identifications, and studies among various religious groups, should contribute to a further understanding of identification processes in relation to the nature of the groups and the intergroup context.

\section{Notes}

1. The other four are, the establishment of daily prayers, concern for and almsgiving to the needy, self-purification through fasting, and, the pilgrimage to Meccah for those who are able. The five pillars of Islam are the foundation of Muslim life.

2. Although this study does not focus on age and gender differences, preliminary analyses were conducted. For age, no systematic differences were found for any of the measures used. However, there were three significant differences for gender. Compared to females, males had a stronger Muslim identification, had more warm thermometer-like feelings towards Muslims, and endorsed Islamic group rights more strongly. No gender differences were found for Dutch identification, and for the feelings towards Christians, Hindustanis, non-believers and Jews.

3. I want to thank the acting editor for this suggestion and example.

\section{References}

Aiken, L. S., \& West, S. G. (1991). Multiple regression: Testing and interpreting interactions. Newbury Park, CA: Sage.

Altemeyer, B. (2002). Dogmatic behavior among students: Testing a new measure of dogmatism. Journal of Social Psychology, 142, 713-721.

Antisemitism Research (2002). Antisemitism incidents in the Netherlands and provisional report for 2002. Amsterdam: Centrum Informatie en Documentatie Israel. 
Argyle, M., \& Beit-Hallahmi, B. (1975). The social psychology of religion. London: Routledge \& Kegan Paul.

Ashmore, R. D., Deaux, K., \& McLaughlin-Volpe, T. (2004). An organizing framework for collective identity: Articulation and significance of multidimensionality. Psychological Bulletin, 130, 80-114.

Barry, B. (2001). Culture and equality. Cambridge, UK: Polity Press.

Batson, C. D., \& Burris, C. T. (1994). Personal religion: Depressant or stimulant of prejudice and discrimination. In M. P. Zanna \& J. M. Olson (Eds.), The psychology of prejudice: The Ontario symposium (Vol. 7, pp. 149-170). Hillsdale, NJ: Erlbaum.

Berry, J. (1984). Multicultural policy in Canada: A social psychological analysis. Canadian Journal of Behavioural Science, 16, 353-370.

Berry, J. W. (2005). Acculturation: Living successfully in two cultures. International Journal of Intercultural Relations, 29, 697-712.

Berry, J. W., \& Kalin, R. (1979). Reciprocity of inter-ethnic attitudes in a multicultural society. International Journal of Intercultural Relations, 3, 99-112.

Blaine, B., \& Crocker, J. (1995). Religiousness, race, and psychological well-being: Exploring social psychological mediators. Personality and Social Psychology Bulletin, 21, 1031-1041.

Blumer, H. (1958). Race prejudice as a sense of group position. Pacific Sociological Review, 1, 3-7.

Bobo, L. D. (1999). Prejudice as group position: Microfoundations of a sociological approach to racism and race relations. Journal of Social Issues, 55, 445-472.

Brewer, M. (1997). The social psychology of intergroup relations: Can research inform practice. Journal of Social Issues, 53, 197-211.

Brewer, M. B. (1999). The psychology of prejudice: Ingroup love or outgroup hate? Journal of Social Issues, 55, 429-444.

Brewer, M. B., \& Pierce, K. P. (2005). Social identity complexity and outgroup tolerance. Personality and Social Psychology Bulletin, 31, 428-437.

Brown, R. (2000). Social identity theory: Past achievements, current problems and future challenges. European Journal of Social Psychology, 30, 745-778.

Cameron, J. (2004). A three-factor model of social identity. Self $\mathcal{E}$ Identity, 3, 239-262.

Cieslik, A., \& Verkuyten, M. (2006). National, ethnic and religious identities: Hybridity and the case of the Polish Tatars. National Identities, 8, 77-93.

Crisp, R. J., Hewstone, M., \& Rubin, M. (2001). Does multiple categorization reduce intergroup bias? Personality and Social Psychology Bulletin, 27, 76-89.

Deschamps, J-C. (1977). Effect of crossing category memberships on quantitative judgement. European Journal of Social Psychology, 7, 517-521.

Dijker, A. (1987). Emotional reactions to ethnic minorities. European Journal of Social Psycholology, 17, 305-329.

Ellemers, N., Spears, R., \& Doosje, B. (Eds.). (1999). Social identity: Context, commitment, content. Oxford, UK: Blackwell.

Entzinger, H. (2003). The rise and fall of multiculturalism: The case of the Netherlands. In C. Joppke \& E. Morawska (Eds.), Toward assimilation and citizenship: Immigrants in liberal nation states (pp. 59-86). London: Palgrave.

Gaertner, S. L., Dovidio, J. F., Anastasio, P. A., Bachman, B. A., \& Rust, M. C. (1993). The common ingroup identity model: Recategorization and the reduction of intergroup bias. European Review of Social Psychology, 4, 3-24.

Gaertner, S. L., Mann, J., Murrell, A., \& Dovidio, J. F. (1989). Reducing ingroup bias: The benefits of recategorization. Journal of Personality and Social Psychology, 57, 239-249.

Haddad, Y. Y., \& Smith, J. I. (2001). Muslim minorities in the West: Visible and invisible. Walnut Creek, CA: Altamira Press.

Hagendoorn, L. (1995). Intergroup biases in multiple group systems: The perception of ethnic hierarchies. In W. Stroebe \& M. Hewstone (Eds.), European Review of Social Psychology (Vol. 6, pp. 199-228).

London: Wiley.

Hewstone, M., \& Brown, R. (1986). Contact is not enough: An intergroup perspective. In M. Hewstone \& R. Brown (Eds.), Contact and conflict in intergroup encounters (pp. 1-44). Oxford, UK: Blackwell.

Hinkle, S., \& Brown, R. J. (1990). Intergroup comparisons and social identity: Some links and lacunae. In D. F. Abrams \& M. A. Hogg (Eds.), Social identity theory: Constructive and critical advances (pp. 48-70). New York: Harvester Wheatsheaf.

Hogg, M. A., \& Abrams, D. (1988). Social identifications. Londodn: Routledge.

Hornsey, M. J., \& Hogg, M. A. (2000). Subgroup relations: A comparison of mutual intergroup 
differentiation and common ingroup identity models of prejudice reduction. Personality and Social Psychology Bulletin, 26, 242-256.

Hutnik, N. (1991). Ethnic minority identity: A social psychological perspective. Oxford, UK: Clarendon Press.

Jackson, J. W., \& Smith, E. R. (1999). Conceptualising social identity: A new framework and evidence for the impact of different dimensions. Personality and Social Psychology Bulletin, 25, 120-135.

Joppke, C. (2004). The retreat of multiculturalism in the liberal state: Theory and policy. British Journal of Sociology, 55, 237-257.

Kahani-Hopkins, V., \& Hopkins, N. (2002). 'Representing' British Muslims: The strategic dimensions to identity construction. Ethnic and Racial Studies, 25, 288-309.

McGarty, C. (2001). Commentary: Social identity theory does not maintain that identification produces bias, and self-categorization theory does not maintain that salience is identification: Two comments on Mummendey, Klink and Brown. British Journal of Social Psychology, 40, 173-176.

Modood, T., Berthoud, R., Lakey, J., Nazroo, J., Smith, P., Bvirdee, S. et al. (1997). Ethnic minorities in Britain: Diversity and disadvantage. London: Policy Studies Institute.

Mullen, B. N., Brown, R., \& Smith, C. (1992). Ingroup bias as a function of salience, relevance, and status: An integration. European Journal of Social Psychology, 22, 103-122.

Ogbu, J. (1993). Differences in cultural frame of reference. International Journal of Behavioral Development, 16, 483-506.

Owen, C., Eisner, H., \& McFaul, T. (1981). A halfcentury of social distance research: National replication of the Bogardus studies. Sociology and Social Research, 66, 80-98.

Phalet, K. (2004). Moslim in Nederland: Religie en integratie [Muslim in the Netherlands. Religion and integration]. The Hague: Sociaal Cultureel Planbureau.

Phalet, K., \& Güngör, D. (2004). Moslim in Nederland: Religieuze dimensies, etnische relaties en burgerschap: Turken en Marokkanen in Rotterdam [Muslim in the Netherlands. Religious dimensions, ethnic relations and citizenship: Turks and Moroccans]. The Hague: Sociaal Cultureel Planbureau.

Phinney, J. S. (1992). The multigroup ethnic identity measure: A new scale for use with adolescents and young adults from diverse groups. Journal of Adolescent Research, 7, 156-176.

Roccas, S., \& Brewer, M. B. (2002). Social identity complexity. Personality and Social Psychology Review, 6, 88-106.

Rothgerber, H., \& Worchel, S. (1997). The view from below: Intergroup relations from the perspective of the disadvantaged group. Journal of Personality and Social Psychology, 73, 1191-1205.

Ryder, A. G., Alden, L. E., \& Paulhus, D. L. (2000). Is acculturation unidimensional or bidimensional? A head-to-head comparison in the prediction of personality, self-identity, and adjustment. Journal of Personality and Social Psychology, 79, 49-65.

Sanchez, J. I. \& Fernandez, D. M. (1993). Acculturative stress among Hispanics: A bidimensional model of ethnic identification. Journal of Applied Social Psychology, 23, 654-668.

Scheepers, P. M., Gijsberts, M., \& Hello, E. (2002). Religiosity and prejudice against ethnic minorities in Europe. Review of Religious Research, 43, 242-265.

Schnabel, P. (2000). De multiculturele illusie: Een pleidooi voor aanpassing en assimilatie [The multicultural illusion: A plea for adaptation and assimilation]. Utrecht, The Netherlands: Forum.

Tajfel, H., \& Turner, J. C. (1986). The social identity theory of intergroup behavior. In S. Worchel \& W. Austin (Eds.), Psychology of intergroup relations (pp. 7-24). Chicago, IL: Nelson-Hall.

Ter Wal, J. (2004). Moslim in Nederland: Publieke Discussie over de Islam in Nederland [Muslim in the Netherlands: Public discussion about Islam in the Netherlands]. The Hague, The Netherlands: Sociaal en Cultureel Planbureau.

Triandis, H. C. (1992). Comments on Hinkle, Brown and Ely. Revista de Psicología Social, 3, 113-123.

Turner, J. C. (1999). Some current issues in research on social identity and selfcategorization theories. In N. Ellemers, R. Spears, \& B. Doosje (Eds.), Social identity: Context, commitment, content (pp. 6-34). Oxford, UK: Blackwell.

Turner, J. C., \& Reynolds, K. (2001). The social identity perspective in intergroup relations: Theories, themes and controversies. In R. Brown \& S.L. Gaertner (Eds.), Blackwell handbook of social psychology: Intergroup processes (pp. 133-152). Oxford, UK: Blackwell. 
Verkuyten, M. (2005). The social psychology of ethnic identity. London: Psychology Press.

Verkuyten, M., \& De Wolf, A. (2002). Ethnic minority identity and group context: Self-descriptions, acculturation attitudes and group evaluations in an intra- and intergroup situation. European Journal of Social Psychology, 32, 781-800.

Verkuyten, M., Hagendoorn, L., \& Masson, K. (1996). The ethnic hierarchy among minority and majority youth in the Netherlands.

Journal of Applied Social Psychology, 26, 1104-1118.

Verkuyten, M., \& Yildiz, A. A. (2006). The endorsement of minority rights: The role of group position, national context, and ideological beliefs. Political Psychology, 27, 527-548.

Verkuyten, M., \& Zaremba, K. (2005). Inter-ethnic relations in a changing political context. Social Psychology Quarterly, 68, 375-386.

Vertovec, S., \& Rogers, A. (Eds.). (1999). Muslim European youth: Reproducing ethnicity, religion, and culture. Aldershot, UK: Ashgate.
Ward, C., \& Rana-Deuba, A. (1999). Acculturation and adaptation revisited. Journal of Cross-Cultural Psychology, 30, 422-442.

Warminska, K. (1997). Polish Tartars: Ethnic ideology and state policy. In C. Govers \& H. Vermeulen (Eds.), The politics of ethnic consciousness (pp. 343-366). London: Macmillan.

Zolberg, A. R., \& Long, L. W. (1999). Why Islam is like Spanish: Cultural incorporation in Europe and the United States. Politics and Society, 27, 5-38.

Paper received 7 March 2005; revised version accepted 7 December 2005.

\section{Biographical note}

MAYKEL VERKUYTEN is a professor at the faculty of social sciences at Utrecht University. He is also a senior researcher at the European Research Center on Migration and Ethnic Relations (ERCOMER) at the same university. 